\title{
Watershed models and their applicability to the simulation of the rainfall-runoff relationship
}

\author{
A. N. Hadadin \\ Department of Civil Engineering, The Hashemite University, Jordan
}

\begin{abstract}
With the rapid advancement in computer and information technologies, computer modeling has become a vital tool in watershed research and management practices. This paper presents a brief review of the development and application of watershed hydrologic models through the past five decades. The purpose of this study is to apply the Stanford Watershed Model (SWM) to estimate the rainfall-runoff relationship for the Wala valley (catchment area $\left.1800 \mathrm{~km}^{2}\right)$. The SWM has been widely accepted as a tool to synthesis a continuous hydrograph of hourly or daily streamflow. Many meteorological and hydrological data and several hydrologic parameters are required as input data. Sensitivity analysis and a trail and error adjustment technique are used for optimization of the number of parameters of the model. Comparison between estimated and measured surface runoff for the Wala valley indicates that the model is considerably efficient in predicting the total annual surface runoff from rainfall.

Keywords: watershed modeling, watershed hydrology, rainfall-runoff relationship, continuous hydrograph, streamflow, Stanford Watershed Model, surface runoff.
\end{abstract}

\section{Introduction}

Watershed models range widely in complexity. Some are nothing more than simple empirical equations, others perform a complex accounting of soil moisture and water in various stages of runoff. Hydrological models are divided broadly into two groups; the deterministic models seek to simulate the physical processes in the catchment involved in the transformation of rainfall to streamflow, whereas stochastic models describe the hydrological time series of 
the several measured variables such as rainfall, evaporation and streamflow involving distribution in probability.

Hydrologic synthesis technique is a powerful tool for aiding engineers and hydrologists in evaluating surface water resources. Since rainfall data is generally in abundance in comparison to runoff data, the attempt has been made to convert rainfall to runoff. Probably one of the best-known Rainfall-runoff models is the Stanford Watershed Model (SWM). It has been widely accepted as a tool to synthesis a continuous hydrograph of hourly or daily streamflow.

Many research workers throughout the world have studied extensions of the unit hydrograph principles. One of the most searching and fundamental contributions was made by Dooge [1]. Concentrating on linear mechanisms, he suggested that the response of catchment could be modeled by combining storage effects with translation effects. Inflows were obtained by the time-area method and used as distributed inputs to generalized network of linear channels and reservoirs.

A team of workers led by Eagleson [2] at the Massachusetts institute of technology (MIT) developed models using linear storages and linear channels, with several simultaneous, but different, inputs at different points in the models. The MIT models are called distributed models. The IUH for this sequence is given by the sum of the impulse responses for each reservoir and channel combination.

A different approach to determining runoff from a catchment was initiated by Laurenson in Australia [3]. He also was tackling the problem of estimating floods from ungaged catchments; the runoff-routing method he adopted gives the complete hydrograph, not just the peak flow as in the empirical formulations.

In conjunction with the Natural Environment Research Council Flood Studies, the Hydraulics Research station at Wallingford developed a simple method to derive flood hydrograph from storm rainfall [4]. The first stage of FLOUT employs the unit hydrograph method. Based on the analysis of records from many UK Catchments, the unit hydrograph is computed from recorded rainfall and runoff data for gaged catchments or from catchment characteristics for un-gaged basins.

The first major computer study to synthesize the discharge of a river was made by Linsley and Crawford [5] at Stanford University in the late 1960s. They aimed to simulate the whole of the land phase of the hydrological cycle in a catchment. The first Stanford watershed Model was soon superseded by new versions as development and experience in application brought about improvements in performance and accuracy. A great variety of data is fed into the model, which is usually programmed to produce daily river flow. Provision is made for dealing with snowmelt and, in incorporating particular of impervious area; the model can be applied to urban studies. Further elaboration compared to the O'Donnell [6] model is the subdivision of the soil moisture storage into an upper zone, from which interflow feeds into channel flow, and a lower zone, which feeds down to the groundwater storage. Evapotranspiration is allowed at the potential rate from the upper zone soil moisture storage but at a rate less than potential from the lower zone and groundwater storage. The total streamflow is 
the sum of overland flow and interflow, derived by separate procedures, and baseflow from the groundwater storage. There are 34 parameters in the Stanford watershed Model IV, but most of these are obtained from physical measurements either of initial conditions or of specific catchment characteristics. Four of the parameters, infiltration and interflow indices together with the capacities of the upper and lower zone soil moisture storage, must be determined by calibration of the model with recorded data. If the snowmelt routing is omitted, the number of parameters reduces to 25 .

In the UK the water Resources Board's model DISPRIN [7] (Dee Investigation simulation program for Regulating Networks) was developed for the River Dee regulation research program. The catchment is envisaged in three hydrological zones, the uplands, the hill slopes and the lower valley areas, designated bottom slopes. In each of the three zones, non- linear storage are interconnected by linear routing procedures representing over land flow and interflow (quick return flow), and these feed into a common ground water storage from which there is baseflow. There are 21 parameters for the DISPRIN model, but seven of these are starting values for the seven storages. The basic form of the model is used for small or medium sized catchment, but the drainage of a large basin can be simulated in sequence of applications.

The Institute of Hydrology mode in the UK has several different forms and can be applied over hourly or daily time periods. Although classed as a simple model, it pays particular attention to the complexities of soil moisture storage, which it represents in several layers. In addition to numerous reported studies at the Institute of Hydrology, a modified form of the model was used to investigate the effects of change in land use on East African catchment [8]. The Lambert model, developed in the former Dee and Clwyd River Authority essentially for small upland catchment, was forerunner of DISPRIN for the Dee Research program and is proving simpler to operate in practice [9]. HYSIM, developed by Manley and used in the Directorate of Operations of the Seven Trent Water Authority, is one of a suite of programs for hydrological analysis and provision of information for design and operational purposes [10]. It operates mainly on daily values of areal rainfall and potential evaporation, and produces daily values of streamflow, but the time period can be flexible. It may be used for the extension of flow data records and data validation, real time flow forecasting and flood studies, modeling of groundwater, and has also simulated successfully daily and monthly flows on ungaged catchments. The Boughton model for small or medium sized catchments was originally developed in Australia for assessing water yield from catchments in dry regions [11]. Hence its immediate concern was with quick runoff. Murray [12] modified the model to include a delayed response interflow and baseflow, and applied it to the Brenig catchment in North Wales as part of the study program carried out by the water Research Association in the late 1960s. The model operates on daily rainfall and evaporation to produce daily runoff [12].

The Stanford Watershed Model and the Boughton [11] Model have already been mentioned as originating in the USA and Australia, respectively. In addition to these pioneering studies and those of MIT, a great amount of work on 
conceptual or deterministic modeling has been carried out by the large Federal Government agencies of the USA with their teams of hydrologists, mathematicians and engineers working full-time with considerable resources. The book edited by Singh [13], which is so far the most comprehensive and detailed compilation of representative, watershed hydrologic models developed in many countries around the world. Although personal bias was unavoidable as admitted by the editor, Singh [13] did a good job in selecting the twenty-six popular models and inviting the original author(s) of each model from several countries (including the USA, Canada, England, Denmark, Sweden, Australia, China and Japan) to contribute a book chapter which describes their models in details. However, notable contributions have been made in other countries in smaller government departments, in commercial organizations and by individuals or small groups in universities.

A single event model is one that is used primarily for individual storm events, although it may be of long duration and multi-peaked. Two factors usually constrain their use to single events: the continuity of soil moisture (loss rates) isn't simulated, and or the model simulates in such detail and requires time consuming computations so that it is not economical to run over long periods.

Some of the most widely used single events models are cited in DeVries [14] and McCuen [15]. Because of this strong interest in relating watershed model parameter to geographic characteristics, the Soil Conservation service's (SCS) [16] curve number technique has received much increasing interest and usage. The SCS curve number technique is the only one in which both the precipitation loss rate and the water excess to runoff transformation (unit hydrograph) can be determined from readily available geographic data. The data used are: land cover, hydrologic soil type, average slop of the watershed, and length of the main watercourse. Curve numbers have been recommended for various land cover.

\section{The Stanford Watershed Model}

Most of today's highly sophisticated continuous watershed is Stanford Watershed Model. Another model, developed at about the same time, is the SSARR model of the Corps of Engineering. The SSARR model does not have all of the complexity of the Stanford derived models. The Stanford watershed Model has been elaborated upon at several universities: Kentucky, Texas, Ohio, and others. Notable among these is the Kentucky version, entitled OPET, where the parameters of the model are derived automatically by an optimization routine. The National weather service also used the Stanford watershed Model as the basis for its NWSRFS model. The National Weather Service Sacramento Model has more comprehensive soil moisture accounting algorithms, but may be considered less sophisticated in its runoff transformation via linear unit graphs and the fact that it does not route streamflow in a comprehensive river system. One of the most highly developed versions, of the Stanford water Model existing today is the Hydrocomp HSP Model. The HSP system of programs incorporates the precipitation- runoff model as one piece of an array of study tools ranging 
from water quality simulation to unsteady flow dam break flood routings. One of the simplest and most economical to run continuous water shed models is the STORM program. The model was originally developed by water resource Engineers, Inc. in connection with storm water runoff in the city of San Francisco. The original model was essentially a long-term hyetograph analysis with a simply rational formula type transformation to runoff [17].

\section{Available data}

1) Rainfall data: All the rainfall stations have been registered and named by the agencies concerned in accordance with the drainage systems. There are 12 rainfall stations in the Wala watershed. Most of these stations have been operating for period up to 20 years. The rainfall records for these station consist of few thousands of autographic charts the personnel of Water Authority of Jordan (WAJ) had reduced the mass curves on the recording charts to monthly abstracts presenting the data as hourly precipitation.

2) Evaporation data: WAJ and Meteorological Department have operated 4 evaporation stations in the area. Evaporation pans of US weather Bureau class-A of 10 in number have been installed and observed in and around the study area since 1960 .

3) Other meteorological data: Other meteorological data such as air temperature (daily - maximum and minimum), sunshine hour are observed at meteorological stations operated by Meteorological Department since 1962.

4) Hydrological data: Existing water level/ discharge record, baseflow, runoff coefficient. According to the WAJ runoff ratio ranges from $4 \%$ in the desert area to $15 \%$ in the northern and western parts of the study area.

\section{Model structure}

The SWM is made up of a sequence of computation routine for each process in the hydrologic cycle (interception, infiltration, routing, and so on) all the moisture that was originally stored in the watershed or was input as precipitation during any time period is balanced in the continuity equation. The Stanford water model utilizes a hydrologic watershed routing technique to translate the channel inflow to the watershed outlet. The change in storage in each zone is calculated as the differences between the volume of inflow and outflow.

\section{Rainfall analysis}

Twelve weather stations have been established in the Wala watershed. These stations measure daily rainfall with one-station measures the streamflow at the outlet of the watershed. The existing data for precipitation is collected from these stations, the periods of rainfall data of the 12 stations varied from one station to another with some missing data. The S.W.M program required hourly rainfall depth, daily streamflow daily maximum and minimum temperature $\left(\mathrm{F}^{\mathrm{o}}\right)$ as input data in order to simulate the synthetic streamflow. 


\subsection{Watershed parameter}

There are some parameters for Wala watershed, which were determined from a topographic map. Those parameters are:

- The watershed drainage area (AREA), which was already computed from a map of $(1: 50,000)$.

- The average ground slope of overland flow (OFSS).

- The mean length of overland flow (OFS, length of overland flow is computed by the following method:

OFSL $=1 /(2 \mathrm{D})$, where $\mathrm{D}$ is the drainage density, $\mathrm{D}=$ the total length of stream with a catchment divided by the drainage area. By the aid of map the total length of stream $=480$ mile. $\mathrm{D}=480 / 695=0.69$. OFSL $=0.72$ mile $=$ $3800 \mathrm{ft}$.

- The fractional stream and lake surface area (FWTR).

- The impervious fraction of the watershed surface draining directly into the stream (FIMP).

- Elevation of catchment above thermometer (ELDIF) (which is the average elevation of catchment (ft)-Elevation of thermometer station (ft)/1000).

Other parameter values such as (CHCAP) channel capacity, no criteria exists for easily obtaining CHCAP from maps, it is assumed to be equal to the maximum flood event happened in the record for Wadi Wala that is $3000 \mathrm{cfs}$.

Manning's roughness parameters for flow over soil and impervious surfaces are both required as input to the program.

For the Wadi Wala the initial estimates for overland flow (OFMN) and impervious surface flow (OFMNIS) were 0.010 and 0.013 , representing coefficients for light turf for over land flow and smooth concrete for impervious surface. After several trials and adjustments the values of (OFMN) and (OFMNIS) are 0.05 and 0.02 respectively.

Ratio of normal basin rainfall to normal station rainfall (RGPM) or multiplier for adjusting recorded precipitation, and (RGEXP) are assumed to be equaled 1.0 because we deal with the depth of rainfall over the total watershed not the depth of rainfall for certain rainfall station in the Wadi.

\section{Trial and adjustment parameters}

Several of the following parameters are determined by trial and adjustment until the comparison between simulated and recorded streamflow is satisfactory. Guidelines for establishing initial values exist for only a few of the parameters, whereas most are initially determined from suggested ranges.

For Wala watershed the parameter and initial estimates are as follows:

VINTMR: the maximum interception rate (in/hr) for a dry watershed. Crawford and Linsley suggest trial values of $0.10,0.15$ and 0.20 for grasslands, moderate forest cover and heavy forest covers respectively. The value of 0.05 was selected for wadi wala watershed, because the surface of the vegetative cover is very small.

BUZC: an index of the surface capacity to store water as interception and depression storage. This parameter normally ranges from 0.10 to 1.65 a greater 
number might be indicative or the forest cover. The value of 0.10 was determined for this parameter after several trials and adjustment.

SUZC: an index of soil surface moisture storage capacity, representing the additional moisture storage capacity available during warmer months due to vegetation. Depending on the soil type, the index ranges from 0.45 to 2.0. A value of 0.45 was determined for wadi wala watershed after several trials.

LZC: a soil profile moisture storage index (in) approximately equal to the volume of water stored above the water table and below the ground surface. The LZC index depending on porosity and the specific yield of the soil, ranges from 2.0 to 20.0 and 4 in plus half the mean annual rainfall can be used as an initial estimate in areas experiencing seasonal rainfall (used in coasted humid or semi humid climates. Assume an initial value for LZC equal to one quarter of the mean annual rainfall plus 4 in (used in arid and semi arid regions). A final value of 4.75 in was determined after several trials.

ETLF: a soiled evaporation parameter that controls the rate of evapotranspiration losses from the lower soil zone. The parameter ranges from 0.20 to 0.90 depending on the type and extent of the vegetative cover. Also ETLF is approximately equal to the fraction of the basin covered by forest and deep-rooted vegetation. Recommendations for barren ground, grassland and heavy forest are respectively $0.20,0.23$ and 0.30 .the value of 0.20 was selected for the wala watershed.

SUBWF: a parameter controlling the fraction of moisture lost or diverted from active groundwater storage through transverse flow across the drainage basin boundary. It also represents that portion of the groundwater that percolates to the deep or inactive groundwater. The SUBWF parameter can be estimated from observed changes in deep groundwater levels, or it is often assumed to be zero because these losses are small compared to the magnitudes of rainfall and runoff.

GWETF: The fraction of the total watershed over which evapotranspiration from groundwater storage is assumed to occur at the potential rate. This parameter is assumed zero unless a significant quantity of vegetation draws water directly from water table. It was selected zero because water table in the wadi wala basin is far to be reached by the plants roots.

SIAC: a factor, ranging from 0.10 to 4.0 that relates infiltration rates to evaporation rates. This parameter simply allows a more rapid infiltration rate recovery during warmer seasons. Value of 3.0 was optimal for wadi wala, after several trials.

BMIR: an index that controls the rate of infiltration, depending on the soil permeability and the volume of moisture that can be stored in the soil. This index ranges from 0.1 to 1.2 . A smaller value was optimal for wadi wala after running several values.

BIVF: an index controlling the time distribution and quantities of moisture entering interflow. This index ranges from 0.55 to 4.5 . A value of 0.955 was selected to Wala watershed, after several trials.

BFNLR: a daily baseflow recession adjustment factor used to produce a simulated curvilinear baseflow recession. An initial value of 1.0 for wadi wala 
was selected. Later adjustments might be required in matching simulated and recorded baseflow recessions. After several trials of optimization it was found to be 0.99

UZS: the current volume (in) of soil surface moisture as interception and depression storage. Because the simulation begins on October of the first calibration year, the parameter may initially be designated as zero unless precipitation occurs during the last few days of September.

0.05 in. was optimal value for Wala stream.

LZS: the current volume (in) of soil surface moisture storage between the land surface and water table. $10 \%$ of LZC was selected to initiate the wadi wala simulation. After several trials of optimization, its best value was 0.50 .

GWS: the current groundwater slope index. This index provides an indication of antecedent moisture condition. Suggested initial values fall between 0.15 and 0.25 . A value of 0.15 was optimal value for Wala watershed.

\section{Output from SWM}

Comparison between recorded and synthesized monthly totals streamflow are shown in Figures 1 and 2 for the water year 2003-2004 and 1989-1990 respectively.

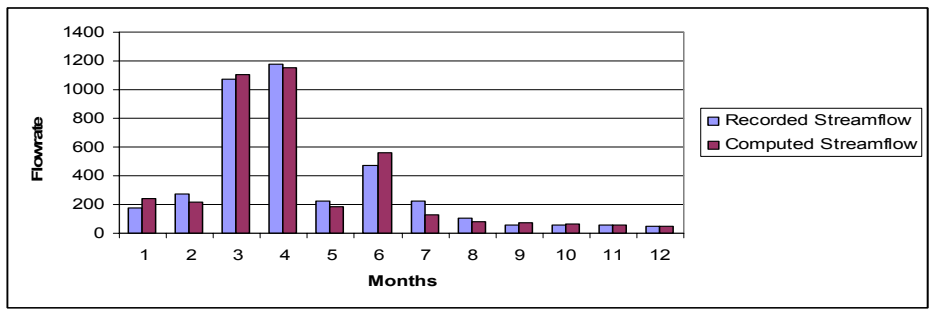

Figure 1: Comparison between monthly totals of synthesized and recorded flow rate for the water year 2003-2004.

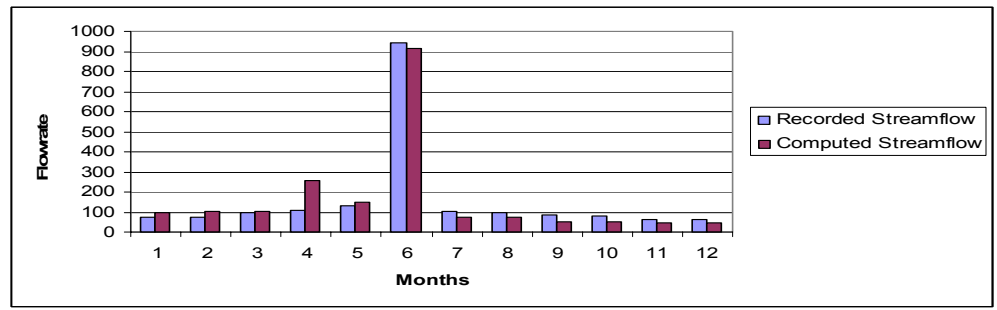

Figure 2: Comparison between monthly totals of synthesized and recorded flow rate for the water year 1989-1990.

At first the SWM is applied on the normal water year 2003-2004. The result shows a good agreement between recorded and synthesized annual streamflow volume. A summation of annual recorded streamflow is about 3950 SFD and the 
synthesized stream flow 3920 SFD. The absolute difference is less than $1 \%$. The sum of the recorded precipitation for the year is about 6.20 in., the synthesized annual evaporation is about $5.55 \mathrm{in}$. A depth of $0.21 \mathrm{in}$. discharged as runoff. Dry year 1989-1990 was adopted using the same parameters the results show that the annual recorded streamflow 1930 SFD, and the synthesized streamflow is about 1960 SFD. The absolute difference is about $1.5 \%$.

\section{Conclusion}

Rainfall precipitation is the primary source of water for streamflow runoff. The characteristics of the watershed govern losses within the watershed and the portion of that precipitation not lost results in surface runoff. Various techniques may be used to relate precipitation to corresponding runoff, these technique vary in complexity, as a general rule, the shortest the time period of runoff to be simulated, the more complex and sophisticated model. SWM is one of these complex models. It was applied in this research on Wala valley watershed. The choice of a model is based on the availability of records for a particular watershed. In the study the relationship between rainfall and runoff is studied by the aid of a computer program depending on the calibration and optimization of watershed parameters.

There are some differences between recorded and synthesized streamflow (of course hydrologic forecasts can not be $100 \%$ accurate). There are many sources of forecast error may be attributed. The influence of man power plays an important role, the change due to construction the dame on Wala stream causes heterogeneous of the catchment area, basic data error in the historic basic data on which the values of watershed parameters depend on, disunity of rainfall pattern, and insufficiency of the density of the rainfall station. This study drew several conclusions:

1. SWM can be applied on Wala watershed to predict the total annual streamflow and peak flood since there is a good agreement between recorded and predicted streamflow.

2. It is concluded that SWM will be accurate if it is applied on very small watershed, where you deal with one rainfall station and streamflow station, and the variety of characteristics of the watershed (geology, topography, land used, vegetation cover) is very small.

3. The model can produce results when properly calibrated. The model is difficult to calibrate because of the large number of parameters and the mass of data processing. It was difficult to know the starting values for several parameters, but this should be easier with experience.

4. The data requirements are extensive both in quantity and in the labor necessary for preprocessing.

5. The model is relatively easy to operate in terms of input instructions, file organization and manipulation.

6. The model is best studied for comprehensive river basin studies requiring analysis of both high and low flows. 
7. The model can be used for all sizes of catchment, and where there are data shortages, regional values of the required inputs may be used. It has been applied to catchments throughout the world and with its great flexibility has helped to provide hydrological information for problems in civil engineering design and agricultural engineering.

\section{References}

[1] Dooge, J. C.I. (1959). A general theory of the unit hydrograph. J.Geophys. Res., 64(2), pp: 241-256.

[2] Bravo, S.C.A., Harley, B.M., Perkins, F.E. and Eagleson, P.S. (1970). A linear Distributed Model of Catchment Runoff. MIT Dept. of Civil Engineering Hydrodynamics Lab., Report No. 123.

[3] Laurenson, E. M., (1964). A catchment storage model for runoff routing. J Hydrol. 2, pp: 141-163.

[4] Price, R.K. (1978). FLOUT a river catchment flood model. Hydraulic Research Station Report No. 168, 2nd imp. Wallingford, England.

[5] Crawford, N. H., and Linsley, R. K., (1966). Digital simulation in hydrology. Stanford Watershed Model IV. Department of Civil Engineering, Stanford.

[6] O'Donnell, T., and Dawdy, D.R., (1965). Mathematical models of catchment behavior. Proc. ASCE. Hy4. 91 pp: 123-127.

[7] Jamieson, D.G and Wilkinson, J.C. (1972). Application of DISPRIN to the River Dee Catchment. Water Res. 8(4), pp: 911.

[8] Blackie, J.R. (1972). The application of a conceptual model to two East Africa Catchments. Unpublished M.Sc. Dissertation. Imperial College.

[9] Lambert, A.O. (1969). A comprehensive rainfall- runoff model for upland catchment area. J. Inst. Water Eng., 23(4), 231-238.

[10] Manley, R.E. (1975). A hydrological model with physically realistic parameters. Proc. Bratislava Symposium, IAHS Pub. No. 115.

[11] Boughton, W.C. (1966). A mathematical model for relating runoff to rainfall with daily data. Trans. Inst. Eng. (Australia), 7, pp: 83.

[12] Murray, D.L. (1970). Boughton's daily rainfall- runoff model modified for the Brenig catchment. Proc. Wellington Symposium, IAHS Pub. No. 144-161.

[13] Singh, V.P. (ed.) (1995). Computer Models of Watershed Hydrology. Water Resources Publications, Highlands Ranch, Colorado, pp: 1130.

[14] DeVries, J.J. and Hromadka, T.V. (1993). Computer models for surface water. In: Handbook of Hydrology, D.R. Maidment (ed.), McGraw-Hill, New York, pp: 21.1-21.39.

[15] McCuen, R.H., (1998). Hydrologic Analysis and Design. 2nd, Prentice Hall Upper Saddle, River, NJ. pp: 814.

[16] The Soil Conservation Service's (SCS, 1984). Computer program for project formulation, Tech. Release No. 20 Washington, DC.

[17] Chen Y. D. (2004). Watershed Modeling: Where are we heading? Environmental Informatics Archives, Vol. 2, pp: 132-139. 